\title{
Identidades em trânsito: uma análise da representação feminina nos contos "Os sapatinhos vermelhos" nas versões de Andersen e Caio Fernando Abreu
}

\author{
Identities in transit: an analysis of the female representation: analysis of the short story \\ "The Red Little Shoes", in the versions of Hans Christian Andersen and Caio Fernando Abreu
}

\section{Identidades en tránsito: un análisis de la representación femenina en los cuentos "Los zapatos rojos" en las versiones de Andersen y Caio Fernando Abreu}

\author{
Livia Maria Rosa Soares $\oplus^{1}$ \\ Vilmaria Chaves Nogueira ${ }^{2} 2$ \\ ${ }^{1}$ Universidade do Estado de Rio Grande do Norte, Pau dos Ferros, RN, Brasil \\ Instituto Federal do Maranhão, São Luís, MA, Brasil. \\ ${ }^{2}$ Universidade do Estado de Rio Grande do Norte Pau dos Ferros, RN, Brasil.
}

\section{RESUMO}

Este trabalho pretende apresentar uma análise comparativa sobre a representação feminina nos contos "Os sapatinhos vermelhos" de Hans Cristian Andersen e no conto homônimo de Caio Fernando Abreu. Verificaremos como os contos, publicados em diferentes épocas, representam e problematizam a condição da mulher frente a conflitos e interdições impostas socialmente. Buscaremos analisar como a narrativa de Caio Fernando Abreu revigora e atualiza o fantástico na pós-modernidade, especialmente ao representar o esfacelamento do sujeito, identidades marcadas pelo duplo, o esmaecimento dos afetos entre outras questões do cenário contemporâneo.

Palavras-chave: Conto clássico. Pós-modernidade. Paródia. Representação feminina.

\begin{abstract}
This work intends to presente a comparative analysis about the female representation in the Short-stories "The Red Little Shoes", by Hans Cristian Andersen, and the homonymous ShortStory by Caio Fernando Abreu. We will verify how both Short-stories, published in diferente periods, represent and problematize the condition of the woman against of the conflicts and sociallu imposed interdictions. We will try to analyze how the narrative of Caio Fernando Abreu invigorates and actualizes the fantastic in postmodernity, especiallu when representing the subject's fragmentation, double identities, weakening of the affection among other issues of the contemporary scenario.
\end{abstract}

Keywords: Classic Short-Story. Postmodernity. Parody. Female representation.

\section{RESUMEN}

Este artículo pretende presentar un análisis comparativo sobre la representación femenina en los cuentos "Los zapatos rojos" de Hans Cristian Andersen y el cuento homónimo de Caio Fernando Abreu. Veremos cómo las historias, publicadas en diferentes momentos, representan y problematizan la condición de la mujer frente a conflictos e interdicciones socialmente impuestas. Analizaremos cómo la narrativa de Caio Fernando Abreu revitaliza y actualiza lo fantástico en la posmodernidad, especialmente cuando representa el desmoronamiento del sujeto, las identidades marcadas por el doble, el desvanecimiento de los afectos, entre otros temas del escenario contemporáneo.

Palabras clave: Cuento clássico. Posmodernidad. Parodia. Representación femenina. 


\section{Introdução}

Este trabalho apresenta uma análise comparativa das identidades femininas no conto "Os sapatinhos vermelhos" de Hans Christian Andersen, publicado em 1845, e no conto homônimo de Caio Fernando Abreu, publicado em 1988. A duas histórias apresentam mulheres que são desafiadas e precisam vencer os dilemas e interdições que a sociedade impõe. Assim, julgamos que o elemento paródico é percebido na obra contemporânea ao promover a reconstrução de discursos tradicionais que representavam mulheres subjugadas e silenciadas frente às imposições sociais.

A forma como as personagens respondem a interdições sociais dão a dimensão dos deslocamentos ideológicos registrados nos últimos séculos. Por essa razão, entender a origem e a evolução dos gêneros fantástico e maravilhoso e a forma com que as identidades aparecem representadas na pós-modernidade estimulam reflexões sobre as transformações do discurso literário ao longo do tempo.

Ambos os autores selecionados para este estudo se notabilizaram pela composição de contos que representaram estruturas sociais que marcaram cada época, sem deixar de lado o minucioso trabalho artístico com a linguagem, o que permite que as histórias transcendam o tempo em que foram escritas. O primeiro, deles, Hans Christian Andersen iniciou sua carreira literária escrevendo peças e contos infantis inspirados no folclore dinamarquês. É um dos escritores mais aclamados quando se fala em obras infantis, na data de seu nascimento, 2 de abril, se comemora o Dia mundial do livro infantil.

A marca inovadora de seus contos incentiva a abordagem de temáticas até então consideradas impróprias para as crianças: o abandono, a morte, especialmente da personagem que representa a bondade, além do temor a Deus, especialmente para destacar o maniqueísmo entre o bem e o mal. Mesmo sem ter seguido o padrão de finais felizes, a poética de Andersen ganha destaque por falar diretamente ao imaginário humano.

O segundo autor selecionado para este estudo é Caio Fernando Abreu, um escritor que "baseava suas obras em experiências individuais, que eram socialmente transgressoras e politicamente subversivas" (PORTO, 2018 , p. 25). O conto foi seu gênero literário por excelência e faz parte do grupo de escritores que usou o caráter alegórico da linguagem literária como forma de resistência durante a ditadura militar no Brasil. Suas personagens ilustram angústias de um mundo demasiadamente excludente, que rotula pessoas trazendo descrença e dor, porém as histórias não terminam com finais alegóricos e exemplares como no passado, o que permite ao leitor vislumbrar o libertador.
Dessa forma, buscaremos entender, a partir da comparação entre os dois contos, como os autores moldaram as identidades de gênero das personagens, o que elas têm a dizer sobre a estrutura social de cada época e como o fantástico, ao apresentar um fato que suplanta o real, instaurando-se o acontecimento insólito: a magia que recobre a personagem após o uso dos sapatos vermelhos.

Esse resgate temático ajuda a representar a melancolia, o abandono e o esfacelamento do sujeito contemporâneo que se sente, muitas vezes, descentrado

\section{Gêneros fantástico e o maravilhoso: um breve histórico}

Imitar, confabular e procurar explicações para as irrupções do sagrado e da natureza sempre pautaram a imaginação criadora de escritores e escritoras que, ao longo do tempo transformaram esse imaginário coletivo em discurso artístico. O mistério do desconhecido sempre pautou e estimulou a criação humana, não importa o quão tecnológica seja a sociedade.

O conto maravilhoso é um gênero que surgiu e se adaptou às características culturais de cada época e, ao mesmo tempo, manteve uma estrutura própria. Esse gênero foi se modificando à medida que os povos iam imprimindo suas culturas e valores nas narrativas (SOARES, 2014).

Na realidade, a gênese da literatura se confunde muito com a vertente fantástica. Sobre isso, Camarani (2014 p. 13) afirma que "as manifestações fantásticas na literatura se confundem com a história do espírito humano ou mais precisamente da imaginação do homem". Irlemar Chiampi (1980) também teorizou a esse respeito, ao analisar o realismo-maravilhoso no romance hispano-americano. Segundo ele, o maravilhoso, que é uma vertente do fantástico, representa uma ausência de causalidade para os acontecimentos sobrenaturais. Há leis e regras que fogem à opinião corrente do que deva a ser a normalidade. $\mathrm{O}$ conto maravilhoso relata acontecimentos impossíveis de se realizar dentro de uma perspectiva empírica da realidade e instaura os acontecimentos sobrenaturais sem questionamentos.

A esse respeito, No artigo "A tensão entre o fantástico e o maravilhoso" a pesquisadora Márcia Romero Marçal (2009) afirma que:

Gêneros como o Maravilhoso, o Estranho, o Realismo maravilhoso e o Fantástico apresentam motivos, personagens e acontecimentos que se referem a uma fenomenologia meta-empírica. Cada qual, no entanto, estabelece uma relação distinta com o meta-empírico segundo a estruturação particular do discurso e dos aspectos narrativos que emprega (MARÇAL, 2009, p. 2). 
Isso significa que, ao representar ações e eventos sobrenaturais, o discurso aponta para si mesmo, se transformando em uma metaficção e pode reverberar reflexões no leitor hipotético para elementos internos da narrativa, porém a partir de elementos externos à obra de arte. A prevalência de situações que irrompem a ordem natural das coisas foi amplamente explorada pelo racionalismo burguês que identifica esses temas com uma cultura primitiva, contrária ao modo de vida civilizado pautado no conhecimento que eles sustentavam.

Assim, estudos apontam forte ligação desse gênero com o mito, o que pode explicar a manutenção de imagens e símbolos. Esses elementos configurados em arquétipos acabam se atualizando no imaginário coletivo, permitindo a manutenção de motivos e temas em narrativas produzidas em momentos diferentes da história.

$\mathrm{O}$ conceito de arquétipo foi introduzido na ciência contemporânea pelo psicanalista Carl Gustav Jung que desenvolveu uma teoria baseada no imaginário, mostrando que valores e costumes repousam em imagens gerais e primordiais que determinam inconscientemente $o$ pensamento, o que ele denomina de arquétipos coletivos. Isto é, o arquétipo em si é imperceptível, um princípio ordenador cujos elementos provenientes do inconsciente coletivo (compostos de conteúdos universais, transpessoais) estruturam e coordenam o funcionamento da psique. Gilbert Durand, um estudioso da teoria junguiana, afirma que esses sedimentos se perpetuam e se atualizam através dos símbolos nas mais diversas manifestações:

[...] o imaginário revela-se muito especialmente como um lugar de "entre saberes". O imaginário implica, portanto, um pluralismo das imagens, e uma estrutura sistêmica do conjunto dessas imagens infinitamente heterogéneas, mesmo divergentes, a saber: ícone, símbolo, emblema, alegoria, imaginação criadora ou reprodutiva, sonho, mito, delírio, etc. (DURAND, 1996, p. 215).

Os contos maravilhosos são gêneros que recuperaram essa herança primitiva e até hoje guardam uma estrutura própria. No passado, ganhou destaque popularizando reis, princesas, bruxas, sereias etc., que ainda hoje encantam leitores em todo o mundo, reafirmando estereótipos.

As histórias marcadas pela exemplaridade funcionavam como instrumento pedagógico que repassavam e ditavam regras. A mulher, muitas vezes, apresentava virtudes pautadas na obediência no ideário patriarcal, as que não seguiam as normas, cometiam falta grave e tinham desfechos marcados por castigos ou até com a morte. Autores como Charles Perrault, Irmãos Grimm e Hans Christian Andersen se notabilizaram no cenário literário ao adaptar e reunir do saber coletivo histórias que apresentavam aos leitores esse confronto entre realidade e imaginação, sempre evidenciando a obediência como virtude.

\section{Os sapatinhos vermelhos de Hans Christian Andersen: a moral burguesa em destaque}

Conforme apresentado anteriormente, o maravilhoso está presente na literatura desde os mais remotos tempos, nesse gênero, as representações femininas sempre tiveram amplo destaque. Por essa razão, ao se analisar narrativas de diferentes povos (mitos, sagas, lendas, narrativas bíblicas, fábulas e contos maravilhosos) os elementos fantásticos são empregados para ajudar a construir e explicar fenômenos que a realidade empírica não consegue desvendar.

Os contos de magia já eram registrados desde a civilização Celta, consoante Coelho (2010) revelavamse como oposição à ideologia cristã, que apresentava o homem como semelhança de Deus. Era preciso valorizar a resignação, a entrega espiritual, mesmo se a história não terminasse com o famoso "felizes para sempre". Ressalte-se que mesmo após um século, os contos de Andersen continuam fazendo parte da seleção de leitura de professores e mediadores de leitura, sendo adaptado para o cinema, inclusive.

Nesse sentido, valores como "É preciso sofrer para vencer", "há forças boas que auxiliam os infelizes", "amor não realizado" são comuns nessas histórias. Essa última aparece sob dois enfoques: primeiramente uma forma de atingir um determinado objetivo, segundo quando contribui para enaltecer a pureza das personagens (VAGULA; SOUZA, 2015).

O conto "Os Sapatinhos vermelhos", a exemplo de "A pequena vendedora de fósforos", "A pequena sereia", "Soldadinho de chumbo" e outros escritos por Andersen, ilustram a morte como elemento de redenção e bondade. A personagem Karen, ao desejar perder a vida por ter se rendido às tentações terrenas do pecado demonstra resignação aos valores religiosos. Esse é o fio condutor da narrativa de Andersen publicada em 1845, protagonizado por Karen, uma garota órfã que vive cercada por imposições religiosas e morais que moldam seu comportamento, sem, contudo, estar atrelada às interferências insólitas e sobrenaturais, sobre isso, Nelly Novaes Coelho reitera que:

$\mathrm{Na}$ verdade a maioria das narrativas de Andersen apresenta personagens, espaço e problemáticas, retirados da realidade comum, conhecida por todos nós. Entretanto, o elemento mágico está em tudo, e tão naturalmente presente, que as coisas passam a acontecer em um espaço onde não existem fronteiras entre o Real e a Fantasia (COELHO, 2010, p. 163). 
Logo no início do conto, a posição do narrador em $3^{\mathrm{a}}$ pessoa, não apresenta um adensamento psicológico da protagonista, traço percebido em algumas narrativas clássicas da época: "uma coisinha pequena e delicada, mas como era muito pobre, precisava andar descalça no verão, no inverno tinha somente um par de sapatos de madeira e seus calcanhares ardiam" (ANDERSEN, 2009, p. 25).

Diante dessa realidade, a esposa de um sapateiro doa à menina um par de sapatos vermelhos feitos com sobras de couro. Logo depois, a mãe adotiva de Karen faleceu e não tendo outros sapatos teve de usá-los durante o funeral, o que gerou grande estranhamento entre os demais habitantes. Após ficar sozinha novamente, a garota vai cuidar de uma senhora idosa e doente. $\mathrm{E}$, ao invés de velar o leito de morte da única pessoa que lhe ofereceu abrigo, Karen resolve usar novamente os sapatos vermelhos para ir ao baile ao invés da igreja, desviando-se do caminho considerado correto, modelo frequente nas funções dos contos de fadas clássicos.

A partir dessa falta, como punição, um anjo corta os pés de Karen para que ela pare de dançar. Os sapatos vermelhos que a fazem cometer o pecado: dançar enquanto a sociedade pedia que ela estivesse de luto era imperdoável, conforme trecho a seguir "Mas não ouviu o que o anjo respondeu, pois os sapatos já a levavam, através do portão, aos campos, cruzando caminhos e atalhos, fazendo-a dançar continuamente, sem interrupção" (ANDERSEN, 2009, p. 13).

A narrativa descreve que a personagem se arrependeu e foi ao padre e pediu que a deixasse trabalhar ali, como criada. Não poderia idealizar adornos ou vestidos bonitos. Os sapatos, usados outrora, representava a vaidade, algo impensável diante da resignação e obediência cristã.

Ao final, não há a certeza sobre o paradeiro dos sapatos não são destruídos, o que simboliza que o poder deles ainda existe. Para Chevallier e Gheerbrant, a cor vermelha simbolicamente representa:

[...] o vermelho é considerado símbolo fundamental do princípio da vida, com sua força, seu poder e seu brilho [...] representa o mistério da vida. É a cor da alma, da libido e do coração. É a cor do interdito aos não iniciados, que os sábios dissimulam sobre seus mantos [...] ele tem o atributo de despertar o desejo. [...] é o lugar da batalha - ou da dialética - entre o céu e inferno, orgiástico, libertador, é a cor de Dioniso (CHEVALLIER; GHEERBRANT, 2016, p. 944-945).

Conforme o exposto, o simbólico e o sobrenatural figuram em toda narrativa como elemento norteador, os sapatos vermelhos que, ao mesmo tempo, representaram a vaidade e libertação efêmera despertam na personagem a coragem de desafiar e quebrar padrões e comportamentos legitimados às mulheres: especialmente o recato e a subserviência. No desfecho, a dor e sacrifício desaparecem e, no céu, haverá a recompensa por todo sofrimento que a personagem viveu: "Sua alma voou ao céu pela escada do sol e ninguém mais falou dos sapatinhos vermelhos" (ANDERSEN 2009, p. 26) Mesmo sem o questionamento sobre as causas dos elementos complicadores da história, eles aparecem como causa das punições as quais a protagonista é vítima, e a incidência desses recursos nos diz muito sobre o inconsciente coletivo presente na época, sobre isso afirma Calvino:

O conto fantástico é uma das produções mais características da narrativa do século XIX e também uma das mais significativas para nós, já que nos diz muitas coisas sobre a interioridade do indivíduo e sobre a simbologia coletiva. A nossa sensibilidade de hoje, o elemento sobrenatural que ocupa o centro desses enredos aparece sempre carregado de sentido, como a irrupção do inconsciente, do reprimido, do esquecido, do que se distanciou de nossa atenção racional (CALVINO, 2004, p. 23).

Após a morte, a garota é perdoada pois se arrependeu do imperdoável pecado. Esse aspecto, como na maioria dos contos maravilhosos, vem carregado de exemplaridade. Segundo Nelly Novaes Coelho, "o fundo moralizantereligioso desta história está bastante claro, mas faz parte de uma época em que tais interditos faziam parte da formação moral do homem" (COELHO, 2010, p. 167).

Por conseguinte, percebeu-se que os valores cristãos e aos ideais burgueses são amplamente explorados. No conto, a protagonista é resignada e conformada com o abandono, os sapatos que a conduzem para uma breve liberdade justificam a amputação de seus membros, o que a faz desejar a morte como forma de evolução. Ela não questiona, não se recusa a sofrer o castigo, apenas aceita as consequências de descumprir sanções sociais e esse ato violento não gera comoção ou revolta de quem convivia com a menina. Por essa razão, mais do que entreter crianças, jovens e adultos, as narrativas maravilhosas clássicas tinham um viés pedagógico e funcionava como um instrumento de dominação, o que diz muito sobre a estrutura social da época em que essas obras foram escritas.

\section{A pós-modernidade na literatura: alguns apontamentos}

A arte é um dos meios mais contundentes de se avaliar os deslocamentos e mudanças no imaginário coletivo em qualquer época, embora ainda não seja um consenso entre estudiosos, definições ainda precisas e unívocas sobre a pós-modernidade. 
Porém um dos elementos comuns dos estudos que tentam descrever essas transformações é a retomada de valores tradicionais, porém atualizados à nova era dos meios de consumo e meios de produção, pois além de descrever e revelar a essência humana, a arte pós-moderna reinterpreta discursos totalizantes. Compagnon (2003, p. 104) afirmava que "se a modernidade é complexa e paradoxal, a pós-modernidade o é igualmente. [...] é a ideologia, ou a não-ideologia da sociedade de consumo".

A pós-modernidade é complexa e paradoxal e pode ser percebida em diversos segmentos: na arquitetura, na história, na economia, história e nas diferentes manifestações artísticas como a literatura. E, tão ambígua quanto sua natureza é sua teorização, por isso, estudiosos como Linda Hutcheon (1991), Frederic Jamerson (2003), Zigman Bauman (2005), Stuart Hall (2005) e vários outros lançaram luz sobre essas transformações, percebendo que todas as obras de arte possuem em comum uma característica contraditória: são todas visivelmente históricas e inevitavelmente políticas, exatamente por associar-se a mudanças profundas no modo de consumo e na circulação de informações.

$\mathrm{O}$ artista ou escritor trabalham sem regras e lutam para incorporar o "não representável" (BAUMAN, 1998) e apontam para os próprios paradoxos e para sua reinterpretação crítica ou irônica em relação à arte do passado. (HUTCHEON, 1991, p. 43). Assim, ao retomar elementos do conto clássico de Andersen, Caio Fernando Abreu aciona essas tendências, confirmando o caráter político da obra de arte, ao fazer ligação com o passado e transformando em palavras o imaginário coletivo vigente. Segundo Foucault, a construção ideológica é sintetizada enquanto há uma relação entre verdade e poder e, assim, todos os discursos podem ser vistos funcionando como regimes de verdade. Segundo o autor,

Cada sociedade tem seu regime de verdade, sua 'política geral' de verdade: isto é, os tipos de discurso que aceita e faz funcionar como verdadeiros; os mecanismos e instâncias que permitem distinguir entre sentenças verdadeiras e falsas, os meios pelos quais cada um deles é sancionado; as técnicas e procedimentos valorizados na aquisição da verdade; o status daqueles que estão encarregados de dizer o que conta como verdadeiro (FOUCAULT, 1993, p. 131).

É possível perceber essa característica também na literatura e, mais especificamente, como objetivo dessa análise na representação das identidades de gênero, uma vez que as verdades ou leis antes tidas como padrões de comportamento e conduta, hoje aparecem reconstruídas, embora ainda lentamente.

Hall (2005, p. 46), examinando as características da identidade do sujeito, no passado e no presente, defende que o "sujeito do iluminismo, que tinha uma identidade fixa e estável foi descentrado, resultado das identidades abertas, contraditórias, inacabadas, fragmentadas do sujeito pós-moderno". O autor defende que essas mudanças são desestabilizadoras sobre as ideias da modernidade tardia e permitem novas definições para a questão da identidade.

Retomamos a afirmação de Compagnon (2013, p. 109) quando defende que "o pós-modernismo reavalia a ambiguidade, a pluralidade e a coexistência dos estilos; cultiva ao mesmo tempo a citação vernácula e a citação histórica. A citação é a mais poderosa criação pósmoderna". Os novos contornos estabelecidos pressupõem uma revisão histórica e cultural atualizada à nova realidade da sociedade de consumo, misturando diferentes códigos e linguagens e redimensionando discursos tradicionais. $\mathrm{O}$ autor defende ainda que estas novas manifestações tinham o desejo de "reunir a arte à vida, ao otimismo tecnológico, ao projeto crítico [...] é o grau zero da cultura contemporânea".

Bauman (2005) afirma que "as identidades ganharam livre curso e agora cabe a cada indivíduo, o homem e a mulher, capturá-las em pleno voo, usando seus próprios recursos e ferramentas". Assim a busca por essas identidades, representa o desejo de viver experiências ainda não vivenciadas e por outro lado o desejo de uma posição fixa. Por essa razão, o autor defende que em um ambiente de vida líquido-moderno, as identidades talvez sejam as encarnações mais comuns, mais aguçadas, mais profundamente sentidas e perturbadoras, por isso são colocadas no topo de seus debates existenciais

Em "A lógica cultural do capitalismo tardio", Frederic Jamerson (2006, p. 42) reitera que "um dos temas mais em voga na teoria contemporânea é o da 'morte' do próprio sujeito, a ênfase correlata seja como descrição empírica no descentramento do sujeito ou psique antes centrados". Isso trouxe como consequência o fim do ego burguês e o esmaecimento dos afetos. Dessa forma, os sentimentos são sustentados por uma peculiar euforia. $\mathrm{O}$ autor defende também o desaparecimento do sujeito individual ao lado de sua consequência formal, a crescente inviabilidade de um estilo pessoal, engendrando uma prática quase universal

Assim, a pós-modernidade também é marcada pela contradição mesmo retomando estruturas antigas, pois ao mesmo tempo em que estabelece laços com o passado, também pode desestabilizá-lo. Ademais, essas tendências permitem investigar a relação da ideologia e do poder com todas as nossas atuais estruturas discursivas.

Contudo, é importante considerar que o caráter subversivo e desafiador tende a ser uma estratégia dos artistas fora do centro (negros, gays, feministas e demais minorias). "Que tenham um acerto de contas e 
uma relação à cultura ainda predominantemente branca, heterossexual e masculina na qual se encontram" (HUTCHEON, 1991, p.58), o que se enquadra na arte como forma de protesto produzida por Caio Fernando Abreu ao relembrar elementos da história clássica de Andersen, parodiando sua estrutura e chamando atenção para o próprio discurso como forma de refletir a condição da mulher na pós-modernidade, pois adquire uma maior liberdade e independência, mas ainda sobre inúmeras interdições.

Dessa forma, Caio Fernando Abreu e outros autores e autoras que escreveram obras contemporâneas repercutiram essas transformações em enredos que representam indivíduos com identidades em transição, marcadas pelo duplo, pela inquietação e angústia de uma sociedade impregnada pelo consumo, produção em massa, intensa circulação de informações e efemeridade das relações, o que confirma a ideia da morte do sujeito unificado e estável. Acerca disso Silva e Leite, ao analisar o duplo em contos de Ignácio de Loyola Brandão, contemporâneo de Abreu inferem que:

Por estarem intrinsecamente relacionadas à temática da identidade, as representações do duplo na Literatura aproximam-se metaforicamente dessa questão, pois se inserem nesse debate maior sobre a construção das identidades ao longo da história. [...] a ilusão da identidade una do Renascimento não encontra mais espaço. Na literatura, o duplo se manifesta na confrontação de duas facetas da mesma personagem (o original e sua cópia) (SILVA; LEITE, 2018, p. 01-02).

Assim, percebe-se que as novas tendências na literatura representam a concretização das transformações históricas e sociais verificadas atualmente, a arte literária como as demais representações artísticas, permitem reflexões sobre a condição humana. É o que se verifica na representação feminina que apresentaremos a seguir no conto de Caio Fernando Abreu, uma personagem marcada pela fragmentação, subjugação e vingança por todas as situações de abandono e solidão que enfrentou ao longo da vida. Caio Fernando Abreu cria uma personagem que oscila entre os padrões impostos e desejos reprimidos na tentativa de reconstruir a própria imagem.

\section{Os sapatinhos vermelhos de Caio Fernando Abreu: identidades em confronto}

O escritor gaúcho, Caio Fernando Abreu, nasceu em 1948 e é reconhecido por sua escrita irreverente, irônica e marcadamente visceral. Nela é possível perceber os dilemas e angústias do sujeito pós-moderno, especialmente ao tratar da solidão, desilusão, descrença do homem contemporâneo, abordando questões pertinentes a toda existência humana. Deu destaque à contracultura, à cultura de massa, à mistura de vozes ao agregar em seus textos elementos do sincretismo religioso, música, cinema, teatro, jornalismo e outras áreas. Atuou numa época em que as liberdades eram cerceadas, por isso a maior parte de seus contos apresentam personagens complexas e paradoxais, marcadas, muitas vezes, pelo duplo.

Além disso, a presença de elementos insólitos estimula o questionamento dos limites entre real/irreal, assim também a passagem da dimensão do cotidiano, do familiar e do costumeiro para a dimensão do inexplicável e do perturbador.

Para Roas (2014), trata-se de uma transgressão que ao mesmo tempo provoca estranhamento em relação à realidade, que deixa de ser familiar e se converte em algo incompreensível e, como tal, ameaçador. A narrativa fantástica nos situa inicialmente dentro dos limites do mundo que conhecemos, do mundo previsível, para logo rompê-lo com um fenômeno que altera a maneira natural e habitual como as coisas ocorrem nesse espaço cotidiano.

Abreu ironiza a herança clássica e atualiza aspectos temáticos do conto "Os sapatinhos vermelhos" originalmente lançado no século XIX, recriando uma mulher que também se sente imersa à sua própria condição de abandono. Inicialmente a protagonista se chama Adelina, uma mulher que aos quarenta anos não se casou, não tem casa própria, não teve filhos e trabalha em um lugar marcado pela burocracia e mediocridade, o vazio marcava sua existência. Sobre essa questão, Bruno Souza Leal infere que:

[...] o mundo dos contos de Caio é a urbe transloucada onde se movem sujeitos, objetos, automóveis, luzes, passado e mito do progresso. A metrópole é o "deslugar" que não permite ao sujeito enraizar-se ou instalar-se. É o lugar para acontecer o inusitado, o estranhamento do mundo, do outro e de si (LEAL, 2002, p. 13).

Conforme o exposto, é comum na contística do autor sujeitos marcados pela exclusão, resultado de uma sociedade voltada para as aparências o que desencadeia, muitas vezes, conflitos existenciais. A frustação pelo rótulo de mulher solteirona e que não obteve sucesso faz de Adelina uma mulher que se sente inferior. O narrador a nomeia "mulher sozinha de quase quarenta anos" ou a "putinha submissa a coreografar jantares à luz de velas" (ABREU, 2018, p.464). A personagem manteve durante cinco anos um relacionamento com um homem casado o que faz com que aumente sua frustração. Além do fracasso na vida amorosa, não realizou nada o que a sociedade espera de uma mulher de 40 anos. Envolta 
em uma estrutura simbólica e patriarcal, ela se limita a esperar a chegada do amante casado, que fortuitamente ia passar algumas noites quando não estava mergulhado na rotina de pai de família. Sobre esse aspecto, retoma-se as considerações de Pierre Bourdieu sobre esses rituais "invisíveis":

O poder simbólico não pode se exercer sem a colaboração dos que são subordinados e que só se subordinam a ele por que o constroem como poder. [...] Assim se percebe que essa construção prática, longe de ser um ato intelectual consciente, livre, deliberado de um sujeito isolado, é, ela própria, resultante de um poder, inscrito duradouramente no corpo dos dominados sob a forma de esquemas de percepção e de disposições (a admirar, respeitar, amar etc.) que o tornam sensível a certas manifestações simbólicas de poder (BOURDIEU, 2001, p. 52-53).

Conforme descrito, os poderes simbólicos moldam o comportamento da personagem, pois essa se sente frustrada por estar presa às condutas que cerceiam o feminino: tolhe sua sexualidade, sua autoestima, seu livrearbítrio. Entretanto, Abreu quebra com a sequência linear de causa e efeito percebida no conto de Andersen: como num passe de mágica, Adelina resolve apagar o cigarro e não derramar mais nenhuma lágrima pelo abandono sofrido. Em um breve momento de epifania, ela decide "desviar o caminho".

A protagonista resolve terminar o relacionamento com o "homem casado da Vila Madalena". Esperou a semana santa: "precisava apressar-se, antes que a quinta virasse sexta-feira santa e os pecados começassem a pulular na memória feito macacos engaiolados: não beba, não cante, não fale nome feio, não use vermelho, o diabo está solto, leva sua alma para o inferno" (ABREU, 2018, p. 465). Esse recurso usado pelo autor, potencializa a impressão que a personagem precisava dessacralizar muitas crenças, tanto internas quanto externas. Adelina "Baixou a cabeça como quem vai chorar. Mas não choraria mais uma gota sequer, decidiu brava $[. .$.$] foi então que$ lembrou dos sapatos..." (ABREU, 2018, p. 467).

Os sapatos vermelhos fariam Adelina romper, como um passe de mágica, com a rotina de esvaziamento do ser que levava. Cumpriu um ritual antes de calçar os sapatinhos vermelhos: perfumou-se e vestiu sua melhor roupa e foi para a noite. "A única mulher sozinha na boate", encontrou três rapazes que a miraram e rotularam "quarentona, carne de segunda, coroa" (ABREU, 2018, p.467). A mulher sentiu-se atraída pelos três desconhecidos, diante da aproximação repentina, um deles pergunta o nome dela: "Eu? Gilda, ela mentiu retocando o batom, estava sendo atriz, mas o fora a vida toda" (ABREU, 2018, p. 469).
A identidade agora é outra, a "quarentona" agora é Gilda, assume outra personalidade, a mulher pacata, submissa e abandonada estava no passado. Essa efemeridade das relações e até da personalidade aparece nos postulados de Bauman, para ele:

Fazer da identidade uma tarefa e o objetivo do trabalho de toda uma vida, em comparação com atribuição de estados da era pré-moderna, foi um ato de libertação - libertação da inércia de costumes tradicionais, das autoridades imutáveis, das rotinas preestabelecidas e das verdades inquestionáveis (BAUMAN, 2005, p.56).

$\mathrm{O}$ autor destaca que essa nova liberdade gera uma autoconfiança, o deslocamento de responsabilidades dos ombros do indivíduo, contribuindo para a crescente indiferença dos poderes superiores em relação às escolhas feitas. Bauman (2005, p. 57) assinala ainda que a força motora por trás desse processo tem sido a acelerada "liquefação" das estruturas e instituições sociais, o que contribui para a fluidez das identidades nesses novos tempos, o que põe em xeque valores e hierarquias sociais.

Gilda, sem tirar os sapatos, se despe de todas as censuras e rótulos que carregava, inicia um ritual de libertação sexual e sentimental naquele dia sagrado para ideologia cristã. $\mathrm{O}$ envolvimento com os três rapazes naquele dia em que "diabo andava solto" deu início a um ritual orgíaco que acabou no apartamento que morava. Após o momento de entrega e extremo prazer, Gilda se sentiu "completamente satisfeita e vingada" (ABREU, 2018, p.471), deixou-se penetrar de todas as formas e deixou-se invadir, se desfez de todo o pudor. Ao final notou que uma joia de brilhante havia sumido, mas não se importou: restaram as marcas e cheiros dos homens que acabara de conhecer.

A transformação de Adelina/Gilda permite associações com mudanças na forma de representação da sexualidade feminina. A personagem aparece como um sentimento de urgência e satisfação, naquela Sexta-feira Santa simbolicamente morreu, ressuscitou e libertou-se do abandono e da condição de "carne de segunda que ninguém queria" (ABREU, 2018, p.471).

A liberação da sexualidade se revelou sem o rótulo de mulher pecadora, uma vez que a relação entre sexo e poder sempre foi constante nas vivências das mulheres, legitimadas por discursos sagrados. Tolher o desejo e a sexualidade feminina é costume de muitas culturas e religiões ainda na atualidade, no entanto, esta narrativa quebra essa tendência ao representar o efeito redentor do uso dos sapatos vermelhos e a realização de suas fantasias sexuais, num mundo ainda marcado pelo conservadorismo, especialmente ao se considerar as condutas femininas. 
O elemento paródico, como teorizou Linda Hutcheon (1991), aparece como uma recuperação crítica do passado, que passa a ser reinterpretado, acomodando outras verdades. A narrativa também contribui para a reconstrução irônica de uma história que, no passado, era marcante pela aniquilação da mulher que se entregou ao desejo de dançar, a punição aplicada à personagem também é percebida no conto de Abreu, porém não com o mesmo teor de violência física.

Adelina/Gilda é rejeitada e chamada de vadia pelo amante, após vê-la com as marcas no corpo causadas pelos parceiros na noite anterior. Essa intertextualidade apresenta-se como uma posição política, chamando a atenção para uma visão particularizada, associada à inquietude de estar no mundo, emoldurando as vivências da personagem sob uma atmosfera fantástica, o que chama a atenção para o caos que a realidade imediata produz e que se reflete na arte.

A personagem demonstra que suas as crenças e tabus ficaram para trás, emoldurando uma outra identidade. No final do conto, Abreu descreve que Gilda dera lugar a Adelina novamente. "Na segunda-feira, já vestida com a roupa sóbria de cores frias para o trabalho, gola fechada" (ABREU, 2018, p.473). As marcas e memórias da noite anterior é o que restaram daquela noite de transformações. No fim, o autor descreve que os sapatinhos continuavam guardados, para quem sabe, em outra sexta-feira fortuita pudessem ser usados novamente.

\section{Considerações finais}

Após a leitura e comparação das duas versões do conto "Os sapatinhos vermelhos", percebemos que ambas despertam debates acerca das representações femininas e dos elementos simbólicos que marcaram cada época. $\mathrm{O}$ uso dos sapatos propiciou às personagens de ambos os contos experiências libertárias: o conto de Abreu, ao retomar alguns elementos do conto maravilhoso de Andersen incentiva a autorreflexividade, o que segundo Hutcheon (1985) é uma das formas mais importantes do discurso interartístico da prática literária metaficcional. Dessa forma, a paródia assume a função de elemento problematizador, permitindo a reavaliação de algumas convenções artísticas, o que permite o estabelecimento de diferenças a partir do paralelismo entre as duas obras.

É possível perceber também uma certa distância crítica, a palavra é reescrita nos moldes de uma obra tradicionalmente conhecida, tendo a memória como fator de interligação entre passado e presente, permitindo ao leitor completar as lacunas e os não ditos a partir da transformação de Adelina/Gilda em relação à obediência e resignação da personagem Karen.
Pelo exposto, percebemos que os dois contos apresentados nesse estudo apresentam personagens femininas com identidades moldadas pelos padrões/ sanções socialmente construídos. Percebeu-se também como os símbolos, arquétipos e alguns elementos estruturais dos contos maravilhosos se mantiveram até mesmo em obras publicadas em séculos diferentes.

Karen, na versão de Andersen, representa os padrões da moral cristã: consente ter as pernas amputadas para não usar mais os sapatinhos que eram símbolos do pecado, da vaidade e da luxúria. Já Adelina/Gilda resgata os sapatos vermelhos do fundo de uma gaveta para que pudessem realizar seu plano de "vingança" contra o aprisionamento, o abandono e os rótulos que lhe eram dados, após um relacionamento com um homem casado por mais de cinco anos, não ter filhos e nem apartamento próprio, era uma mulher que nada representava na hierarquia social.

Outrossim, a recuperação de motivos e temas do conto de Andersen contribui para representar a busca do entendimento do que seja estar-no-mundo no mundo atual, marcado, sobretudo, por uma insegurança resultante de uma sociedade voltada para necessidades artificiais, confirmando as teorias de descentramento e fragmentação do sujeito na pós-modernidade.

Percebeu-se na versão de Abreu que mesmo com a "aparente" igualdade de direitos conquistada pelas mulheres, a violência simbólica e os interditos ideológicos continuam, só que apresentados de forma implícita e por poderes simbólicos. Isso põe em destaque desequilíbrios e desigualdades que a sociedade ainda reproduz.

Ademais, apesar da visível intertextualidade e a técnica paródica na manutenção do título e da simbologia dos sapatinhos vermelhos, há uma distância crítica, uma vez que é possível perceber questões relacionadas ao esvaziamento dos afetos, fluidez das relações, valores e questionamentos sobre a condição feminina no passado e no presente.

Depreende-se que as duas histórias permitem reflexões sobre temas atemporais: a identidade, o duplo, a aparência versus a essência, razão versus emoção, liberdade e aprisionamento, real e irreal.

Karen, personagem do conto clássico, aceitou um destino irremediável, ela própria desejou morrer. Adelina "morre" temporariamente para dar lugar a Gilda, pois ela não terá pudor em realizar todos os seus desejos e fetiches sexuais que reprimia. Nos dois contos, as temáticas retratadas desnudam a alma humana e favorecem reflexões especialmente sobre o descentramento do sujeito pós-moderno e como a arte representa as mudanças de paradigma e mentalidade.

A pós-modernidade se construiu em um terreno movediço e ainda se percebem seus desdobramentos, uma vez que as crenças e valores cristalizados dão lugar ao 
ceticismo, na rejeição do temor divino, às instituições e a discursos totalizantes. Desse modo, a Literatura funciona como instrumento de reflexão, que alaga horizontes, permite ver vários lados e, mesmo silenciosa, permite questionamentos sobre o conservadorismo ainda visível em vários contextos, incentivando a transformação de mentalidades.

\section{Referências}

ABREU, Caio Fernando. Contos completos. Rio de Janeiro: Companhia das Letras, 2018.

ANDERSEN, Hans Christian. Os sapatinhos vermelhos. Disponível em: http://www.4shared.com/file/60606773/ b7a0e6cb/sapatinhos_vermelhos.html?s=1. Acesso em: 06 out. 2018. https://doi.org/10.5216/sig.v16i1.3751

BAUMAN, Z. Identidade. Rio de Janeiro: Zahar, 2005.

BOURDIEU, Pierre. O Poder simbólico. Trad. Fernando Tomaz. Rio de Janeiro: Bertrand Brasil, 2001.

CAMARANI, Ana Luisa S. A literatura fantástica: caminhos teóricos. Araraquara: Cultura Acadêmica, 2014. https://doi. org/10.12957/abusoes.2015.20993

CALVINO, Ítalo. Contos fantásticos do século XIX: O fantástico visionário e o fantástico cotidiano. São Paulo: Companhia das Letras, 2004.

CHEVALIER, Jean; GHEERBRANT, Alain. Dicionário de símbolos: mitos, sonhos, costumes, gestos, formas, figuras, cores, números. 29. ed. Rio de Janeiro: José Olympio, 2016.

CHIAMPI, I. O realismo maravilhoso: forma e ideologia no romance hispano-americano. São Paulo: Perspectiva, 1980. https://doi.org/10.5195/reviberoamer.1982.3719

COELHO, Nelly Novaes. Panorama histórico da literatura infantil juvenil: das origens indo-europeias ao Brasil contemporâneo. 4. ed. rev. São Paulo: Ática, 2003.

COMPAGNON, A. Os cinco paradoxos da modernidade. Belo Horizonte: UFMG 2003.

DURAND, Gilbert. As estruturas antropológicas do imaginário. Lisboa: Presença, 1989.

FOUCAULT, M. Microfisica do poder. Rio de Janeiro: Graal, 1993.

HUTCHEON, Linda. Uma teoria da paródia: ensinamentos das formas de arte do século XX. Trad. de Tereza Louro Pérez. Lisboa: Edições 70, 1985.

HALL, S. A identidade cultural na pós-modernidade. 10. ed. Rio de Janeiro: DP\&A, 2005.

JAMERSON, F. Pós-modernismo: a lógica cultural do capitalismo tardio. 2. ed. São Paulo: Ática, 2006.
LEAL; B. S. Caio Fernando Abreu: A Metrópole e a Paixão do Estrangeiro. São Paulo: Annablume, 2002.

MARÇAL, Márcia R. A tensão entre o fantástico e o maravilhoso. Fronteira Z: Revista do Programa de Estudos Pós-Graduados em Literatura e Crítica Literária, São Paulo, n. 3, PUC-SP, 2009. https://doi.org/10.23925/19834373.2018i20p205-221

ROAS, David. A ameaça do fantástico: aproximações teóricas. Trad. Julián Fuks. São Paulo: Unesp, 2014.

SILVA, Antonia Marly M; Leite, Francisco G. Sob o domínio do duplo: um estudo comparativo de dois contos de Ignácio de Loyola Brandão. Estudos de literatura brasileira contemporânea, n. 54, p. 297-318, maio/ago. 2018. Disponível em: http://www.scielo.br/pdf/elbc/n54/23164018-elbc-54-297.pdf. Acesso em: 5 jan. 2019. https://doi. org/10.1590/10.1590/2316-40185416

SOARES. Lívia Maria Rosa. Representações Femininas nos contos de fadas de Marina Colasanti. Dissertação (Mestrado em Letras) - Universidade Estadual do Piauí, Teresina, 2014.

VAGULA, Vânia K. B; SOUZA, Renata J. A morte na literatura infantil de Hans Christian Andersen. Revista Caderno Seminal Digital, ano 21, v. 1, n. 23, jan.-jun. 2015. https://doi.org/10.12957/cadsem.2015.14510

Recebido em: 22/1/19.

Aprovado em: 12/11/19.

Publicado em: 21/12/2019.

\section{Autoras:}

Livia Maria Rosa Soares

Mestra e doutoranda, Universidade do Estado de Rio Grande do Norte, Pau dos Ferros, RN, Brasil. Instituto Federal do Maranhão, São Luís, MA, Brasil..

Orcid: https://orcid.org/0000-0002-6713-5896

E-mail: livia.soares@ifma.edu.br

Endereço: Campus Avançado Pau dos FerrosI

BR 405, KM 3 - Arizona

59900-000, Pau dos Ferros, RN, Brasil

Vilmaria Chaves Nogueira

Mestra e doutoranda, Universidade do Estado de Rio Grande do Norte Pau dos Ferros, RN, Brasil..

Orcid: https://orcid.org/0000-0002-9807-4846

E-mail: vilmariachaves@hotmail.com 